\title{
The role of learning and experience in the development of dietary choice by sheep and goats
}

\author{
RJ Orr 1, PD Penning 1, AJ Parsons 1, A Harvey 1, JA Newman 2 \\ $1 / G E R$, North Wyke, Okehampton, Devon EX20 2SB, UK ; '2Dept of Zoology, Southern Illinois University, \\ Carbondale, IL 62901-6501, USA
}

To test the role of maternal influence on the development of diet preference, sheep (Scottish Halfbred ewes and Suffolk $x$ twin lambs) and goats (British Saanen does and pure-bred twin kids) grazed four mixed swards of perennial ryegrass (Lolium perenne $L$. cv Parcour) and white clover (Trifolium repens $L$. cv Kent Wild White). Following synchronised parturition, offspring were either reared naturally or cross-fostered between anima! species. The offspring were weaned at 18 weeks of age and they continued to graze the mixed swards (ca $20 \%$ clover) until their preference for grass or clover was tested at 21 weeks. For the test there were 12 plots, each $50 \times 50 \mathrm{~m}, 50 \%$ clover : $50 \%$ grass by area ( $50 \times 25 \mathrm{~m}$ of clover monoculture alongside 50 $\times 25 \mathrm{~m}$ of grass monoculture) each at $6 \mathrm{~cm}$ sward surface height. Groups of four animals were released at 10:30 h onto the dividing line between grass and clover. Each of the four treatments was replicated three times and the preference test ran for $72 \mathrm{~h}$. The behaviour (grazing, ruminating or idling) of one focal animal per group was observed during daylight hours (07:00 to $20: 00 \mathrm{~h})$ and whether it was positioned on grass or clover.
There was no effect of rearing method on live weight at the start of the test; kids and lambs respectively weighed 19.1 and $31.4 \pm 1.51 \mathrm{~kg}$. The mean \% time spent on clover of the total grazing time was significantly higher $(P<0.01)$ in the first $24 \mathrm{~h}$ compared with the following periods and, within each day, was higher early in the morning than the evening. Both kids and lambs reared by ewes tended to have a higher preference for clover than those reared by does and cross-fostered kids tended to have a greater preference for clover than animals on all other treatments. However, neither differences between animal species nor rearing method on preference or total grazing time were significant. Preference for clover in naturally-reared lambs and kids was lower than previously found for adults (Penning et al, 1995, Proc 4th Int Symp Nutr Herbiv, September 1995, Clermont-Ferrand) and not different from $50 \%$, i.e. the proportion offered. Also, total grazing times during daylight were similar on each of the three days, with a mean of $367 \pm 42.7 \mathrm{~min}$. Thus lambs and kids selected a mixed diet, even though a monospecific diet could easily have been obtained.
$\%$ of grazing time on clover

\begin{tabular}{cc}
\multicolumn{2}{c}{ Lamb } \\
Natural & Cross \\
$-\quad 5$ & 51.2 \\
49.7 & 37.4 \\
39.2 & 26.0 \\
45.3 & 38.2 \\
44.8 &
\end{tabular}

\begin{tabular}{cc}
\multicolumn{2}{c}{ Kid } \\
Natural & Cross \\
\hline 63.6 & 72.1 \\
32.9 & 67.5 \\
34.2 & 55.3 \\
43.6 & 65.0
\end{tabular}

